Article

\title{
Charge Injection Characteristics of Semi-Conductive Composites with Carbon Black-Polymer for HVDC Cable
}

\author{
Yanhui Wei ${ }^{1}$, Mingyue Liu ${ }^{1}$, Wang Han ${ }^{1}$, Guochang $\mathrm{Li}^{1,2}{ }^{1}$, Chuncheng Hao ${ }^{1}$ and \\ Qingquan Lei ${ }^{1,2}$ \\ 1 Institute of Advanced Electrical Materials, Qingdao University of Science and Technology, \\ Qingdao 266042, China \\ 2 State Key Laboratory of Electrical Insulation and Power Equipment, Xi'an Jiaotong University, \\ Xi'an 710049, China \\ * Correspondence: lgc@qust.edu.cn
}

Received: 13 May 2019; Accepted: 11 June 2019; Published: 3 July 2019

\begin{abstract}
Semi-conductive composites composed of carbon black-polymer play an important role in uniform electric field in high voltage direct current (HVDC) cable. They also affect space charge behaviors in the insulation material. However, the charge injection characteristics of semi-conductive composites are not detailed. In this work, the electrode structure of 'Semi-conductive compositesInsulation material- Metal bottom' (S-I-M) is proposed, and the currents formed by injected charges from semi-conductive composites are characterized by the thermally stimulated depolarization current (TSDC) method. Further, the experimental results based on the structure of S-I-M are compared with the traditional electrode structure of M-I-M (Metal upper electrode- Insulation material- Metal bottom electrode) and the simplified cable electrode structure of MS-I-M (Metal upper electrode-Semi-conductive electrode- Insulation material- Metal bottom electrode), respectively. The experimental results show that the semi-conductive composite plays an important role in the charge injection process and it presents a different tendency under different compound modes of temperature and electric field. For the low electric field $(E \leq 5 \mathrm{kV} / \mathrm{mm})$ and the low temperature $\left(T \leq 50^{\circ} \mathrm{C}\right)$, the current caused by the accumulated charges follows the rule, $I_{\mathrm{S}}>I_{\mathrm{MS}}>I_{\mathrm{M}}$. For the low electric field and high temperature $\left(T>50^{\circ} \mathrm{C}\right)$, the current caused by the injected charges follows the rule, $I_{\mathrm{MS}}>I_{\mathrm{M}}>I_{\mathrm{S}}$. This phenomenon is closely related to the interface characterization and contact barrier.
\end{abstract}

Keywords: semi-conductive composites; carbon black-polymer; charge injection characteristics; HVDC cable

\section{Introduction}

The semi-conductive layer is an essential component of high voltage direct current (HVDC) cables and plays an important role in the uniform electric field and makes the conductor wire core and the insulation layer connect tightly [1-7]. The semi-conductive composites are mainly composed of ethylene-vinyl acetate copolymer (EVA), low-density polyethylene (LDPE) and carbon black (CB). In the actual application, space charge accumulation in the insulation layer is one of the key factors that threaten the safe operation of the HVDC cable, which can cause local electric field distortion, resulting in the degradation or breakdown of the insulation material. The semi-conductive layer is located between the conductor wire core and the insulation layer. As the electron transport path from the conductor to the insulation material, it affects space charge accumulation in the insulation 
material [8-13]. Hence, it is important to thoroughly understand the charge injection characteristic of semi-conductive composites.

The space charge problem in the cable insulation material has been investigated by theoretical calculation and experimental measurements in many works [1,14-17]. However, most studies ignored the effect of charges injected by the semi-conductive layer, only focusing on the injected charges from the metal electrode, such as the thermally stimulated depolarization current (TSDC), pulsed electroacoustic (PEA) and space charge limited current (SCLC).

In recent years, there have been some studies paying attention to the semi-conductive composites of the HVDC cable mainly from two aspects: the interfacial characterization between the semi-conductive composites and the insulating material, and the modification of semi-conductive material $[2,11,14,18-23]$. For the former, some works have been investigated, including the aging mechanism of the interface between the semi-conductive composites and the insulating material under stress of high voltage, and the relationship between breakdown field strength and insulation structure nearby the semi-conductive composites $[2,11,14]$. For the latter, the influence of the doping ratio of carbon black on the conductivity of the semi-conductive composites has been studied as well as the influence of semi-conductive prescription on the space charge behaviors of the insulation material [18-23].

The above studies all tried to solve the space charge accumulation in the insulation material in the view of the space charge source. However, the injected charges were considered to come entirely from the metal electrode, ignoring the charges injected by semi-conductive material. At present, the charge injection characteristic of the semi-conductive composites in the HVDC cable are not detailed as it is difficult to distinguish the charge injection from the metal electrode and semi-conductive composites. Hence, it is not clear what the contribution of the space charge from the semi-conductive composite is.

In this work, in order to analyze the charge injection characteristics of the semi-conductive composites, the electrode structure of the semi-conductive composites is designed as a high voltage terminal. Then, the currents formed by charges injected by the semi-conductive composites are characterized by the thermally stimulated depolarization current (TSDC) method. Further, the experimental results based on the structure of S-I-M (Semi-conductive composites- Insulation material- Metal bottom) are compared with the traditional electrode structure of M-I-M (Metal upper electrode- Insulation material- Metal bottom electrode) and the simplified cable electrode structure of MS-I-M (Metal upper electrode-Semi-conductive electrode- Insulation material- Metal bottom electrode), respectively. Finally, the charge injection mechanisms with different high voltage terminals are discussed.

\section{Experimental Method and Setup}

\subsection{Preparation of Semi-Conductive Composite}

For the HVDC cable, the semi-conductive layer is a kind of composite, which mainly includes ethylene-vinyl acetate copolymer (EVA), low-density polyethylene and carbon black (CB). The insulation layer is mainly composed of polyethylene (PE), a cross-linking agent. Fourier transform infrared spectroscopy (FTIR) of the semi-conductive composite was implemented is shown in Figure 1.

The results show that there are four typical absorption peaks at $1469 \mathrm{~cm}^{-1}, 1735 \mathrm{~cm}^{-1}, 2850 \mathrm{~cm}^{-1}$ and $2922 \mathrm{~cm}^{-1}$. As can be seen from Figure 1, a strong absorption peak appears near $2922 \mathrm{~cm}^{-1}$ and $2985 \mathrm{~cm}^{-1}$, which are both characteristic absorption peaks of the stretching vibration of $-\mathrm{CH}_{2}$ in PE. The absorption peak near $1735 \mathrm{~cm}^{-1}$ is weak, which is the characteristic peak of -CO stretching vibration in CB or EVA. The absorption peak at $1469 \mathrm{~cm}^{-1}$ is the $-\mathrm{CH}$ telescopic vibration peak in PE. The absorption peaks less than $1000 \mathrm{~cm}^{-1}$ represent the vibrations of small molecular groups, which are not analyzed here [24,25]. 


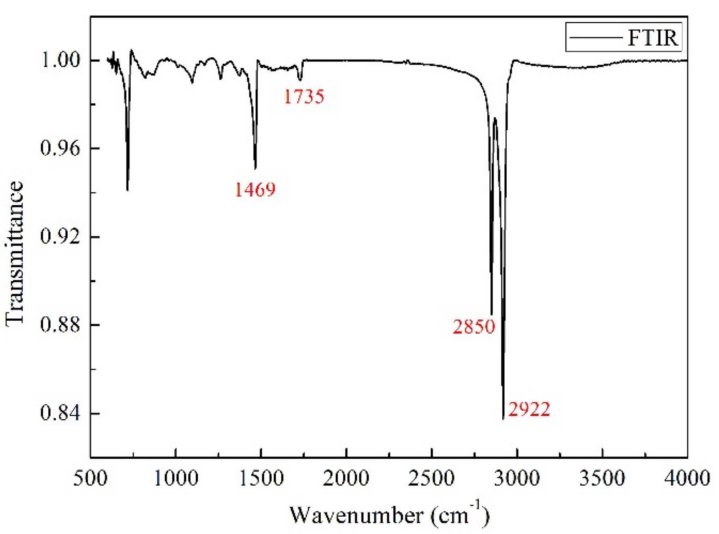

Figure 1. Fourier transform infrared spectroscopy (FTIR) image of semi-conductive composites.

In the experiments, the semi-conductive composites with a thickness of $200 \mu \mathrm{m}$ were prepared by the melt-compounding method. Firstly, the raw materials were dried in a vacuum chamber at $60^{\circ} \mathrm{C}$ for $2 \mathrm{~h}$, and were then molded by a plate vulcanizing press at $110^{\circ} \mathrm{C}$ for $10 \mathrm{~min}$. After that, the cross linked process was implemented by another plate vulcanizing press at $180^{\circ} \mathrm{C}$ for $15 \mathrm{~min}$. Finally, the specimen was cooled for $10 \mathrm{~min}$. Adopting a similar method, cross-linked polyethylene (XLPE) films with a thickness of $300 \mu \mathrm{m}$ were prepared. The dispersion properties of carbon black particles in the polymer matrix were observed by scanning electron microscopy (SEM) and the surface roughness of composites was observed by atomic force microscopy (AFM), as shown in Figures 2 and 3.

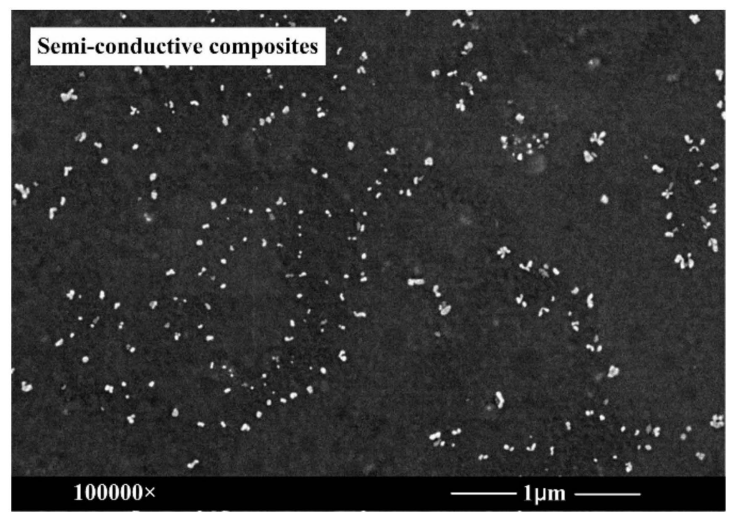

Figure 2. Scanning electron microscopy (SEM) image of semi-conductive composites.

(a)

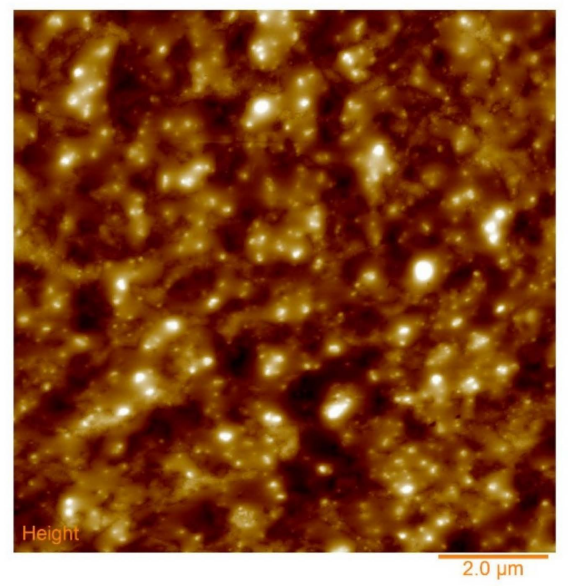

(b)

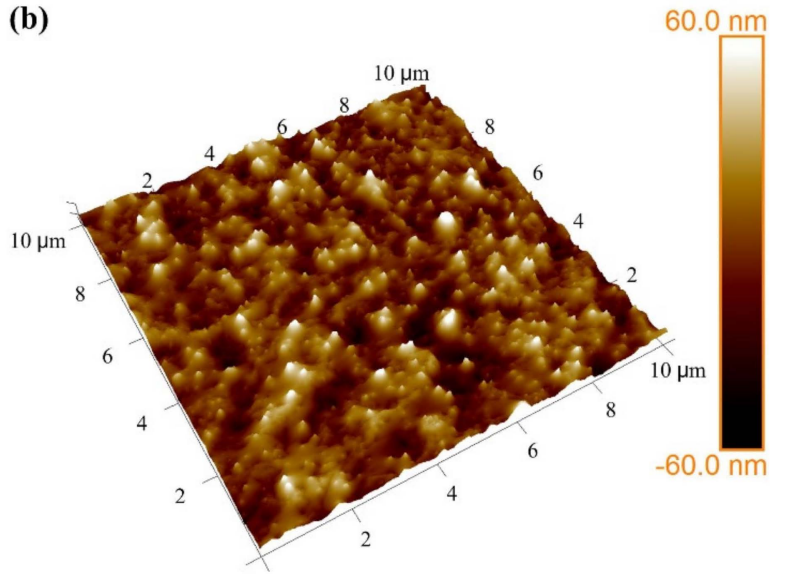

Figure 3. Atomic force microscopy (AFM) image of semi-conductive composites. (a) Two-dimensional distribution; (b) three-dimensional distribution. 
As seen in Figure 2, carbon black particles and white spots were observed clearly. They filled in the polymer matrix, forming the electron conductive channel. Overall, most carbon black particles were dispersed uniformly in the polymer matrix. The surface roughness of the semi-conductive composites had a great effect on the charge emission characteristic, because semi-conductive composites are composed of countless tiny conductive spheres, which can cause the interface electric field distortion between the semi-conductive layer and the insulation layer. From Figure 3a, it can be seen that the average roughness of the semi-conductive composites was $11.9 \mathrm{~nm}$.

\subsection{Test Method and Validation}

In most studies, the traditional electrode structure of 'Metal upper electrode- Insulation materialMetal bottom electrode' (M-I-M) is adopted to study the conductivity property and charge property of the insulation material, as shown in Figure $4 \mathrm{a}$, in which the metal of the high voltage terminal applies voltage on the insulation material. In the actual application, the cable mainly consists of a metal wire core, an inner semi-conductive layer, an insulation layer, an outside semi-conductive layer and a metal armor layer. Among them, the inner semi-conductive layer between the metal wire core and the insulation layer plays an important role in the space charge accumulation property in the insulation layer. Figure $4 \mathrm{~b}$ shows the simplified cable electrode structure of 'Metal upper electrode-Semi-conductive electrode- Insulation material- Metal bottom electrode' (M-S-I-M), in which the metal and semi-conductive layer are a whole high voltage terminal applying voltage on the insulation material. While, it is difficult to distinguish whether the charges accumulated in the insulation material come from the metal electrode or the semi-conductive electrode.

(a)

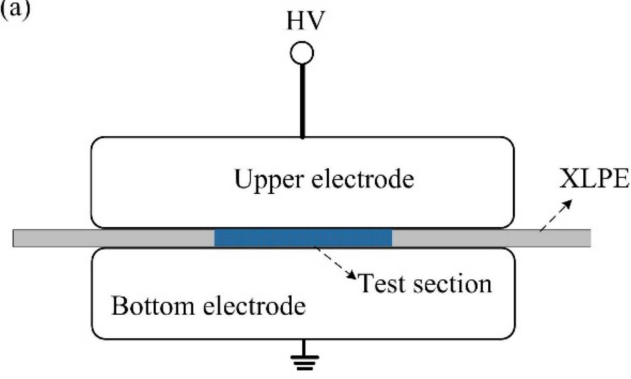

(b)

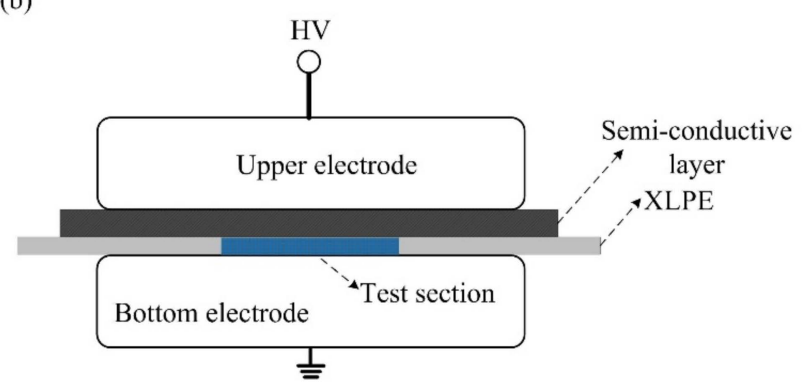

(c) HV

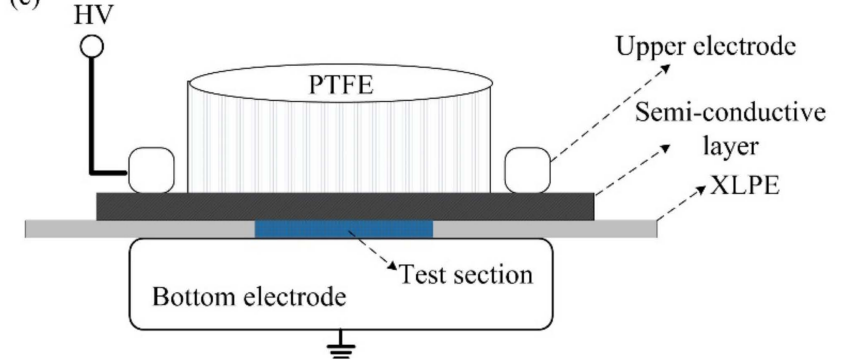

Figure 4. Schematic diagram of electrode structures with different high voltage terminals. (a) The traditional electrode structure of Metal upper electrode- Insulation material Metal bottom electrode (M-I-M); (b) the simplified cable electrode structure of Metal upper electrode-Semi-conductive electrodeInsulation material- Metal bottom electrode (M-S-I-M); (c) the electrode structure of Semi-conductive composites- Insulation material- Metal bottom (S-I-M).

In this work, a kind of electrode structure for assessing the charge emission characteristics of semi-conductive composites was proposed, in which the semi-conductive composites acted as a high voltage terminal applying voltage on the insulation material, as shown in Figure 4c.

For the method, a specific ring structure made of aluminum was designed as the upper electrode, which was connected closely with the semi-conductive layer composed of EVA, LDPE and CB. When applying voltage on the ring structure, the equal potential formed on the semi-conductive 
composites because the resistivity of semi-conductive composites was much lower than that of the insulation material. Figure 5a shows changes of the resistivity of the semi-conductive composites with temperature. It can be seen that the volume resistivity changes from $25 \Omega \cdot \mathrm{cm}$ to $85 \Omega \cdot \mathrm{cm}$ at the test temperature from $25^{\circ} \mathrm{C}$ to $80^{\circ} \mathrm{C}$. While, the volume resistivity of XLPE is around $10^{16} \Omega \cdot \mathrm{cm}$. In order to ensure the charge emission was from the semi-conductive composites rather than the ring structure, the test region of the specimen was much smaller than the ring structure, which is marked in blue in Figure $4 \mathrm{c}$, and the diameter of the test region was $20 \mathrm{~mm}$. Besides, in order to make a good contact between the semi-conductive composites and the specimen, an insulation structure of cylinder made of heat-resisting material of polytetrafluoroethylene (PTFE) with the same weight of the upper electrode in Figure $4 \mathrm{a}, \mathrm{b}$ was placed on the semi-conductive composites.

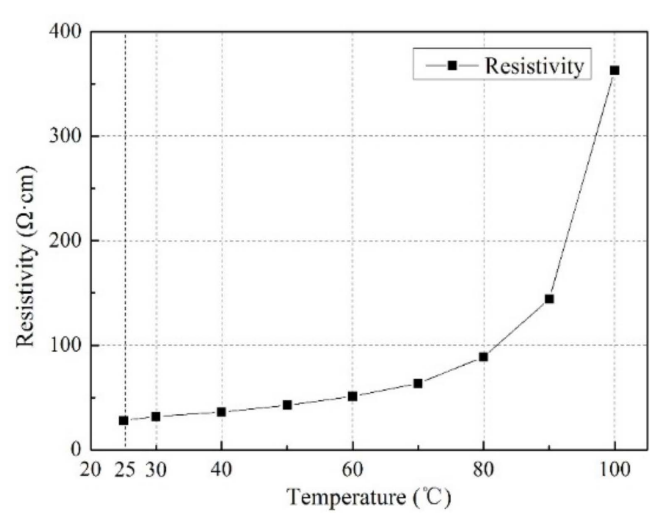

(a)

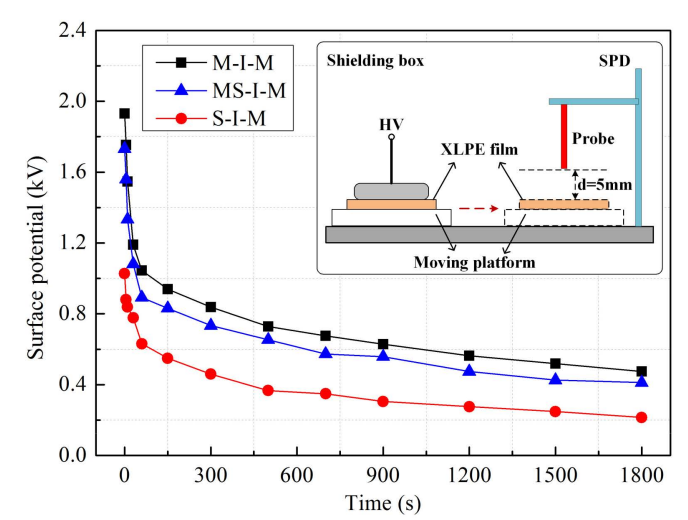

(b)

Figure 5. Test method and validation. (a) Changes of resistivity of semi-conductive composites with temperature; (b) surface potential decay over time of semi-conductive composites under different electrode structures.

In the experiments, the charge injection processes with different high voltage terminals were firstly carried out based on the three-electrode structure. After that, the accumulated charges in the insulation material injected by different high voltage terminals were characterized by thermally stimulated depolarization current (TSDC), which can reflect the changes of the trapped charges in insulation material with the increasing depolarization temperature. For the charge injection processes, three typical polarization temperatures of $25^{\circ} \mathrm{C}, 50^{\circ} \mathrm{C}$ and $70{ }^{\circ} \mathrm{C}$ were considered, two typical electric fields of $5 \mathrm{kV} / \mathrm{mm}$ and $60 \mathrm{kV} / \mathrm{mm}$ were set and four typical compound modes of temperature and electric field were carried out, that is, low temperature and high field, high temperature and low field, low temperature and low field, high temperature and high field. For each compound mode, the electrode structure of S-I-M was placed in a temperature control chamber, and the applying voltage time was $30 \mathrm{~min}$. For the TSDC process, the specimen was taken out at room temperature for the depolarization current measurement. The depolarization temperature changed from $25^{\circ} \mathrm{C}$ to $80^{\circ} \mathrm{C}$, the heating rate was $2{ }^{\circ} \mathrm{C} / \mathrm{min}$. Keeping the same specimen condition and test method, the traditional electrode structure of M-I-M and the simplified cable electrode structure of MS-I-M were carried out.

In order to verify the test method, surface potential decay curves of XLPE stressed of different electrode structures were measured by a non-contact surface potentiometer. In theory, the injected charges in the insulation material are different for different high voltage terminals, and the changes can be reflected by the surface potential, which decays over time after the voltage is removed. Firstly, the specimen was applied voltage under $15 \mathrm{kV} / \mathrm{mm}$ at $25^{\circ} \mathrm{C}$ and the duration of the voltage was $30 \mathrm{~min}$. Secondly, after charging, the specimen was moved instantly to the measuring position via a moving platform. During the measurement, the distance between the probe and XLPE film was set to $5 \mathrm{~mm}$. The surface potential was recorded for $30 \mathrm{~min}$. The measured results are shown in Figure 5b.

It can be seen that the initial surface potential was different for the three types of electrode structures. The maximum surface potential was $1.93 \mathrm{kV}$ caused by the electrode structure of M-I-M, 
followed by the electrode structure of MS-I-M with $1.73 \mathrm{kV}$ and S-I-M with $1.03 \mathrm{kV}$. It indicated that there was an obvious charge injection of the semi-conductive composites. It should be noted that the surface potential decay (SPD) method was only used to verify qualitatively the charge emission characteristics with different electrode structures, because it only reflects the changes of surface charge. In the experiments, the accumulated charges in the insulation material bulk were characterized by the TSDC method.

\section{Experimental Results and Analysis}

In the experiments, two typical electric fields, a low electric field of $5 \mathrm{kV} / \mathrm{mm}$ and a high electric field of $60 \mathrm{kV} / \mathrm{mm}$, were considered. Three typical polarization temperatures of $25^{\circ} \mathrm{C}, 50^{\circ} \mathrm{C}$ and $70{ }^{\circ} \mathrm{C}$ were set and the depolarization temperature was changed from $25^{\circ} \mathrm{C}$ to $80^{\circ} \mathrm{C}$, the heating rate was $2{ }^{\circ} \mathrm{C} / \mathrm{min}$. Figure 6 shows the depolarization current of XLPE polarized using three types of electrode structures under the low electric field.

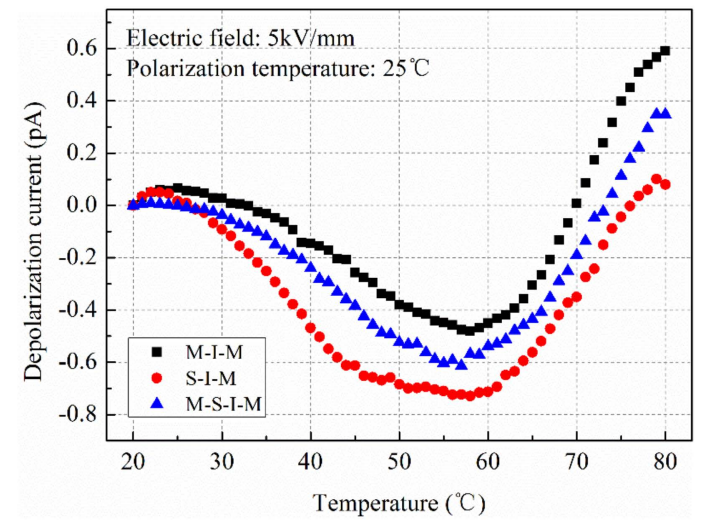

(a)

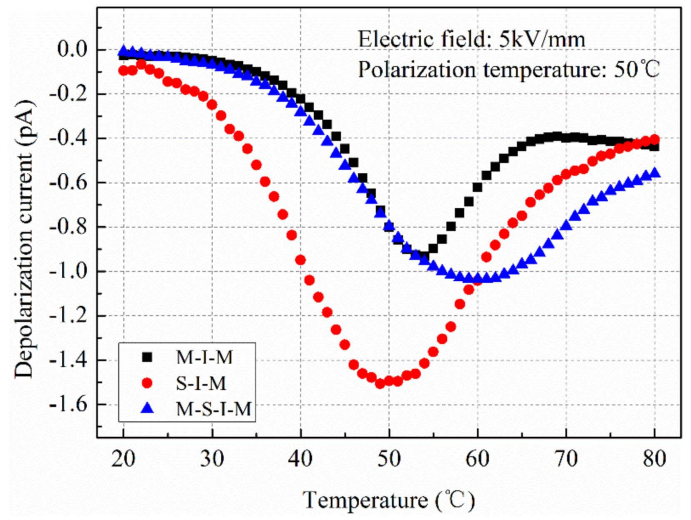

(b)

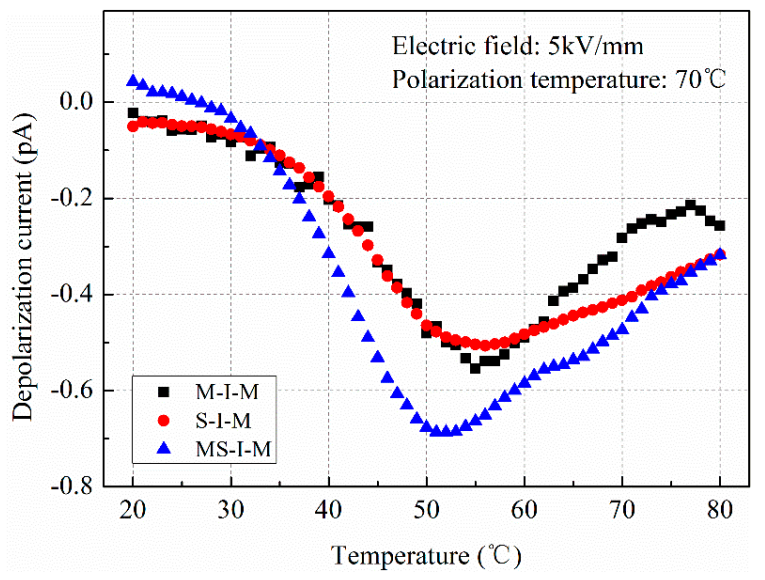

(c)

Figure 6. Depolarization current of cross-linked polyethylene (XLPE) polarized using different electrode structures under low electric field with different polarization temperatures. (a) $25^{\circ} \mathrm{C}$; (b) $50{ }^{\circ} \mathrm{C}$; (c) $70^{\circ} \mathrm{C}$.

Generally, depolarization currents of dielectric mainly have contribution from the dipole depolarization process and de-trapping process of the captured charges [26]. For different electrode structures, dipole depolarization processes are the same because the same voltages are applied on the insulation material. While, the charge injection processes are different, these charges will struggle gradually against the trap centers with the increasing temperature. Hence, the depolarization current can represent the injected charges from different high voltage terminals. As shown in Figure 6, for the three electrode structures, the depolarization current firstly increases, and then decreases with the increasing depolarization temperature, and the maximum current appears at around $50{ }^{\circ} \mathrm{C}$ to $60^{\circ} \mathrm{C}$. 
Besides, the maximum depolarization currents made changes when polarization temperatures were different for the three electrode structures, which illustrate the effects of temperature on the injected charge from the metal electrode and semi-conductive electrode are different. When the polarization temperature is lower than $50^{\circ} \mathrm{C}$, the injected charges from the semi-conductive electrode are obviously larger than that from the metal electrode. It illustrates that the semi-conductive composites play a great significant role in the charge injection process, as shown in Figure $6 \mathrm{a}, \mathrm{b}$. The maximum current caused by the injected charges from the semi-conductive composites was $0.8 \mathrm{pA}$ at $25^{\circ} \mathrm{C}$, and the value increased to $1.51 \mathrm{pA}$ at $50{ }^{\circ} \mathrm{C}$. When the polarization temperature exceeded $50^{\circ} \mathrm{C}$, it was found that the charge emission characteristics were different for the three electrode structures. The charges from the electrode structure of MS-I-M were larger than that of M-I-M and S-I-M, the maximum current was $0.69 \mathrm{pA}$ at $70^{\circ} \mathrm{C}$, as shown in Figure $6 \mathrm{c}$.

In the experiments, the insulation specimens polarized under a high electric field of $60 \mathrm{kV} / \mathrm{mm}$ were also carried out, adopting the three types of the electrode structures, and the total charges were calculated by the TSDC curves [26]. Figure 7 shows total charge amount as a function of the polarization temperature in XLPE stressed of different electrode structures. Comparing the two cases of low electric field and high electric field, it was observed from Figure 7a that when the polarization temperature was lower than $50^{\circ} \mathrm{C}$, the charges from the semi-conductive composites were obviously larger than that from the metal electrode. When the polarization temperature exceeded $50{ }^{\circ} \mathrm{C}$, the charges from the whole electrodes of 'MS' became evident, while the charges from the semi-conductive composites cannot be ignored, since both of them had the same order. The phenomenon was closely related to the interface characterization and the contact barrier among the metal, the semi-conductive composites and the insulation material. It can be observed from Figure $7 \mathrm{~b}$ that for different polarization temperatures, the total charges all present the consistent variation trend, that is, the charges from the electrode structure of MS-I-M were the most among the three electrode structures. The same phenomenon occurred at the low electric field and high temperature, as shown in Figure 7a.

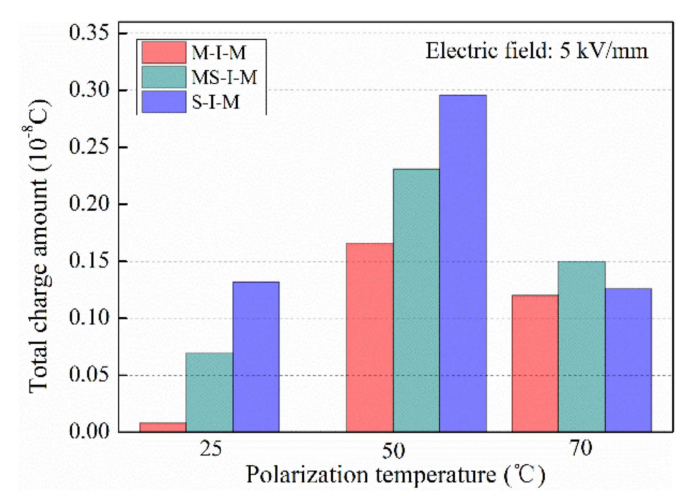

(a)

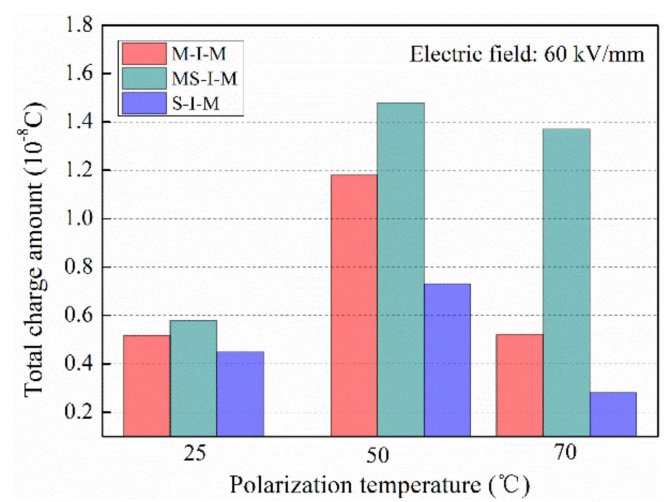

(b)

Figure 7. Total charge amount as a function of the polarization temperature in XLPE stressed of different electrode structures. (a) Low electric field of $5 \mathrm{kV} / \mathrm{mm}$; (b) high electric field of $60 \mathrm{kV} / \mathrm{mm}$.

Comparing the three types of electrode structures, it can be summarized that the semi-conductive composite a significant influence on charge accumulation in the insulation material, and for different compound modes of temperature and electric field, the charge injection characteristics from the semi-conductive composites were different. Figure 8 shows a schematic diagram of charge injection from different high voltage terminals. Here, the low electric field refers to how the applied electric field is lower than $5 \mathrm{kV} / \mathrm{mm}$, and the relatively low temperature refers to how the polarization temperature is lower than $50{ }^{\circ} \mathrm{C}$. For the low electric field and the low temperature, the depolarization current follows the rule, $I_{\mathrm{S}}>I_{\mathrm{MS}}>I_{\mathrm{M}}$. For the low electric field and high temperature, the rule becomes $I_{\mathrm{MS}}>I_{\mathrm{M}}>I_{\mathrm{S}}$. 
(a)
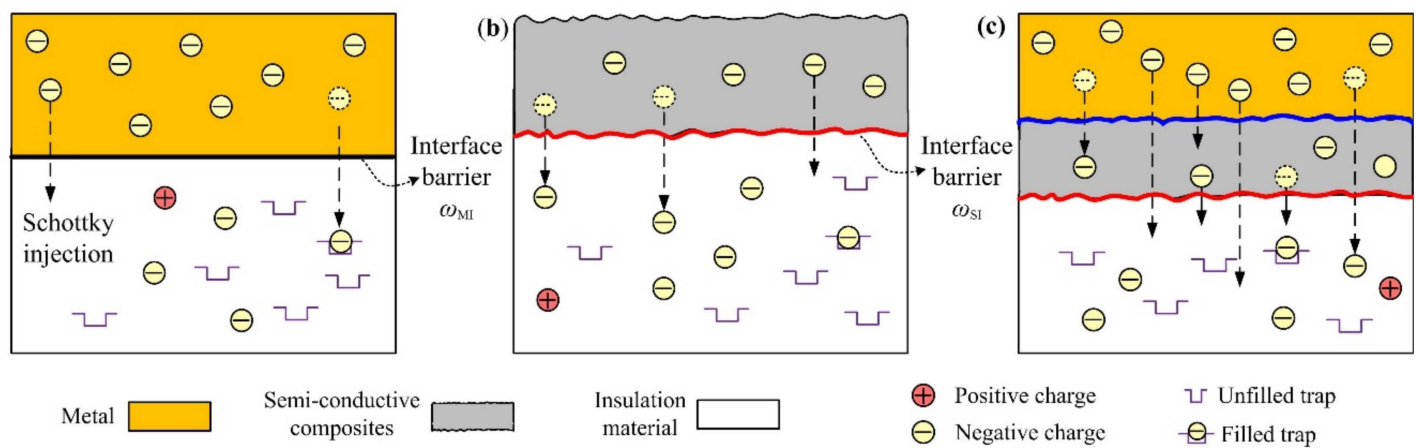

Figure 8. Schematic diagram of charge injection from different high voltage terminals. (a) M-I; (b) S-I; (c) MS-I.

For the low electric field and the low temperature, it was difficult to obtain sufficient energy for the electrons in the metal electrode to overcome the interface barrier between the metal and the insulation material, hence the injected charges from the traditional electrode structure were few, as shown in Figure 8a. For XLPE, the charge injection electric field at the room temperature was around $10 \mathrm{kV} / \mathrm{mm} \mathrm{[14].} \mathrm{While} \mathrm{the} \mathrm{charge} \mathrm{injection} \mathrm{characteristic} \mathrm{was} \mathrm{different} \mathrm{for} \mathrm{the} \mathrm{semi-conductive}$ composites, which consist of countless tiny carbon black particles (see Figure 2), as shown in Figure 8b. From the AFM image in Figure 3a, it can be seen that the average roughness of the semi-conductive composites was $11.9 \mathrm{~nm}$. These tiny bump structures on the semi-conductive composites surface can cause the interface electric field distortion between semi-conductive composites and the insulation material, resulting in the lower injected barrier. Hence, the charges can be easily injected from the electrode structure of S-I-M under the condition of the low electric field and the low temperature.

For the low electric field and high temperature or the case of the high electric field, the charges from the whole electrode structure of MS-I-M were the largest among three electrode structures, as shown in Figure 8c. This is because most charges in the metal and semi-conductive composites could get enough energy under the effect of temperature and electric field to overcome the interface barrier and inject into the insulation material, especially for the high temperature of $70{ }^{\circ} \mathrm{C}$ or the high electric field of $60 \mathrm{kV} / \mathrm{mm}$. By contrast, for the electrode structure of M-I-M, there was no contribution of charges injected by semi-conductive composites. Besides, the interface barrier between the metal and insulation material was higher than that between the semi-conductive composites and the insulation material, which led to the injected charges from the electrode structure of M-I-M being less than that of the electrode structure of MS-I-M. It also implied that the semi-conductive composite plays a key role during the process of charge exchange.

In addition, the maximum charge amount all appears at the polarization temperature of $50{ }^{\circ} \mathrm{C}$, which has a close link with the charge transport of trapping and de-tapping in the insulation material, as shown by the charge transport processes in the insulation material in Figure 8. A similar phenomenon has also been found in LDPE stressed by the metal electrode [26]. At room temperature, it is difficult for the captured charges to release from the trap sites, resulting in the accumulation of homo-charges near the cathode, thus depressing the further injection of the charges. When the temperature exceeds about $50{ }^{\circ} \mathrm{C}$, the charge movement is accelerated which can enhance the hopping probability of charges between the adjacent traps, resulting in less charge accumulation.

\section{Conclusions}

In conclusion, the injection charge characteristics with different high voltage terminals (S-I-M, M-I-M and MS-I-M) were investigated by the thermally stimulated depolarization current method. The conclusions are drawn as follows:

(1) For the low electric field $(E \leq 5 \mathrm{kV} / \mathrm{mm})$ and the low temperature $\left(T \leq 50{ }^{\circ} \mathrm{C}\right)$, the current caused by the injected charges follows the rule, $I_{\mathrm{S}}>I_{\mathrm{MS}}>I_{\mathrm{M}}$. The phenomenon can be explained in 
that it is difficult for the electrons in the metal electrode to overcome the interface barrier between the metal and the insulation material. While, for semi-conductive composites, the charges can be injected to the insulation material because of countless tiny conducting spheres, which can cause the interface electric field distortion between semi-conductive composites and the insulation material, resulting in the lower interface barrier.

(2) For the low electric field $(E \leq 5 \mathrm{kV} / \mathrm{mm})$ and high temperature $\left(T>50^{\circ} \mathrm{C}\right)$ or the case of a high electric field, the current caused by the injected charges follows the rule, $I_{\mathrm{MS}}>I_{\mathrm{M}}>I_{\mathrm{S}}$. This can be interpreted as how most charges in the metal and semi-conductive composites can get enough energy to overcome the interface barrier. By contrast, for the electrode structure of M-I-M, there is no contribution of injected charges from semi-conductive composites and the interface barrier between the metal and insulation material is higher than that between the semi-conductive composites and the insulation material.

Author Contributions: Y.W., G.L. and Q.L. put forward the idea and designed the experiments; Y.W., M.L. and W.H. implemented the experiments; G.L. and C.H. provided support for the analysis of the experimental results.

Funding: This work was supported by China Postdoctoral Science Foundation (Grant No. 2018M642627), Shandong Provincial Natural Science Foundation, China (Grant No. ZR2018BEE029), National Engineering Laboratory for Ultra High Voltage Engineering Technology (Grant No. NEL201802) and State Key of Advanced Electromagnetic Engineering and Technology (Grant No. 2018KF002).

Conflicts of Interest: The authors declare no conflict of interest.

\section{References}

1. Carstensen, P.; Farkas, A.A.; Campus, A.; Nilsson, U.H. Electric characterization of films peeled from the insulation of extruded HVDC cables. IEEE Conf. Electr. Insul. Dielectr. Phenom. 2005, 79-82. [CrossRef]

2. Rogti, F.; Mekhaldi, A.; Laurent, C. Space charge behavior at physical interfaces in cross-linked polyethylene under DC field. IEEE Trans. Dielectr. Electr. Insul. 2008, 15, 1478-1485. [CrossRef]

3. Tanaka, T.; Okamoto, T.; Hozumi, N.; Suzuki, K. Interfacial improvement of XLPE cable insulation at reduced thickness. IEEE Trans. Dielectr. Electr. Insul. 1996, 3, 345-350. [CrossRef]

4. Zhang, Z.; Assala, P.D.S.; Wu, L.H. Residual life assessment of 110 kV XLPE cable. Electr. Power Syst. Res. 2018, 163, 572-580. [CrossRef]

5. Okamoto, T.; Ishida, M.; Hozumi, N. Dielectric breakdown strength affected by the lamellar configuration in XLPE insulation at a semiconducting interface. IEEE Trans. Dielectr. Electr. Insul. 1989, 24, 599-607. [CrossRef]

6. Li, L.; Han, B.; Song, W.; Wang, X.; Lei, Q. The effect of the semiconductive screen on space charge suppression in cross-Linked polyethylene. Chin. Phys. Lett. 2014, 31, 112-115. [CrossRef]

7. Vissouvanadin, B.; Roy, S.L.; Teyssedre, G.; Laurent, C.; Denizet, I.; Mammeri, M.; Poisson, B. Impact of concentration gradient of polarizable species on the electric field distribution in polymeric insulating material for HVDC cable. IEEE Trans. Dielectr. Electr. Insul. 2011, 18, 833-839. [CrossRef]

8. Zhou, Y.; Peng, S.M.; Hu, J.; He, J.L. Polymeric insulation materials for HVDC cables: Development, challenges and future perspective. IEEE Trans. Dielectr. Electr. Insul. 2017, 24, 308-1318. [CrossRef]

9. $\mathrm{Fu}, \mathrm{M}$.; Chen, G. Space charge measurement in polymer insulated power cables using flat ground electrode PEA system. IEE Proc.-Sci. Meas. Technol. 2003, 150, 89-96. [CrossRef]

10. Fabiani, D.; Montanari, G.C.; Laurent, C.; Teyssedre, G.; Morshuis, P.H.F.; Bodega, R.; Dissado, L.A. HVDC cable design and space charge accumulation. Part 3: Effect of temperature gradient. IEEE Electr. Insul. Mag. 2008, 24, 5-14. [CrossRef]

11. Delpino, S.; Fabiani, D.; Montanari, G.C.; Laurent, C.; Teyssedre, G.; Morshuis, P.H.F.; Bodega, R.; Dissado, L.A. Polymeric HVDC cable design and space charge accumulation. Part 2: Insulation interfaces. IEEE Electr. Insul. Mag. 2008, 24, 14-24. [CrossRef]

12. Tian, F.; Lei, Q.; Wang, X.; Wang, Y. Effect of deep trapping states on space charge suppression in polyethylene/ZnO nanocomposite. Appl. Phys. Lett. 2011, 99, 142903. [CrossRef]

13. Han, B.; Wang, X.; Sun, Z.; Yang, J.M.; Lei, Q. Space charge suppression induced by deep traps in polyethylene/zeolite Nanocomposite. Appl. Phys. Lett. 2013, 102, 012902. [CrossRef] 
14. Fabiani, D.; Montanari, G.C.; Laurent, C.; Teyssedre, G.; Morshuis, P.H.F.; Bodega, R.; Dissado, L.A. Polymeric HVDC cable design and space charge accumulation. Part 1: Insulation/semicon interface. IEEE Electr. Insul. Mag. 2007, 23, 11-19. [CrossRef]

15. Suzyoki, Y.; Matsukawa, Y.; Han, S.O.; Fujii, A.; Kim, J.S.; Mizutani, T.; Ieda, M.; Yoshifuji, N. Study of space-charge effects on dielectric breakdown of polymers by direct probing. IEEE Trans. Dielectr. Electr. Insul. 1992, 27, 758-762. [CrossRef]

16. Hozumi, N.; Suzuki, H.; Okamoto, T.; Watanabe, K.; Watanabe, A. Direct observation of time-dependent space charge profiles in XLPE cable under high electric fields. IEEE Trans. Dielectr. Electr. Insul. 1994, 1, 1068-1076. [CrossRef]

17. Tressaud, A.; Durand, E.; Labrugere, C.; Kharitonov, A.P.; Kharitonova, L.N. Modification of surface properties of carbon-based and polymeric materials through fluorination routes: From fundamental research to industrial applications. J. Fluor. Chem. 2007, 128, 378-391. [CrossRef]

18. Roy, M.; Nelson, J.K.; Maccrone, R.K.; Schadler, L.S.; Reed, C.W.; Keefe, R.; Zenger, W. Polymer nanocomposite dielectrics-the role of the interface. IEEE Trans. Dielectr. Electr. Insul. 2005, 12, 629-643. [CrossRef]

19. Li, Z.; Du, B.; Han, C.; Xu, H. Trap modulated charge carrier transport in polyethylene/graphene nanocomposites. Sci. Rep. 2017, 7, 4015. [CrossRef]

20. Nilsson, U.H.; Boström, J.-O. Influence of the semi-conductive material on space charge build-up in extruded HVDC cables. Conf. Rec. IEEE Int. Symp. Electr. Insul. 2010, 1-4. [CrossRef]

21. Van der Born, D.; Tsekmes, A.; Person, T.J. Evaluation of space charge accumulation processes in small size polymeric cable models. Annu. Rep. Conf. Electr. Insul. Dielectr. Phenom. 2012, 669-672. [CrossRef]

22. Han, S.J.; Wasserman, S.H. Agglomeration and percolation network behavior of semi-conductive polymer composites with carbon nanotubes. IEEE Int. Symp. Electr. Insul. 2010, 1-4. [CrossRef]

23. Zhang, Z.; Niu, F.; An, Z.; Zheng, F.; Ma, P.; Lei, Q. Space charge injection in LDPE by semi-conductive electrode with different carbon black filling rates. High Volt. Eng. 2011, 37, 1904-1909.

24. Xie, K.; Chen, D.; Cai, X.; Hou, B.; Zhang, Z. Study on the practical characterization of the microstructure of polyethylene by infrared spectroscopy. China Synth. Resin Plast. 2005, 1, 48-52.

25. Ji, J. Characterization of Carbon Black Surface. Carbon 1999, 4, 8-12.

26. Li, G.; Wang, J.; Han, W.; Wei, Y.; Li, S. Influence of temperature on charge accumulation in low-density polyethylene based on depolarization current and space charge decay. Polymers 2019, 11, 587. [CrossRef] [PubMed]

(C) 2019 by the authors. Licensee MDPI, Basel, Switzerland. This article is an open access article distributed under the terms and conditions of the Creative Commons Attribution (CC BY) license (http://creativecommons.org/licenses/by/4.0/). 